\title{
The Effect of Facebook on Academic Performance for Undergraduate Students at Charmo University
}

\author{
Hardi M. M-Saleh (1), Zrar Kh. Abdul (2), Azad Abdullah Ameen (3) \\ (1) Charmo University, College of Basic Education, Computer Department,Chamchamal, Raperin, Iraq \\ hardi.mohammed@charmouniversity.org \\ (2) Charmo University, College of Basic Education, Computer Department, Chamchamal, Raperin, Iraq \\ zrar.abdul@charmouniversity.org \\ ${ }^{(3)}$ Charmo University, College of Basic Education, Computer Department, Chamchamal, Raperin, Iraq \\ azad.ameen@charmouniversity.org
}

\begin{abstract}
Facebook occupies an important part of people's time and life due to the recent developments in the field of communication technologies (CT). This paper aims at investigating the Facebook impact (FI) on undergraduate students at Charmo University. Moreover, Facebook also has a great impact on students' life studies at universities. However, in addition to its benefits, Facebook also has some side effects on students' life study. In regard to data collection, an online survey was used in which 15 questions were answered by 100 participants from different faculties at Charmo University. The data collection process was conducted from First of March to 30 of April 2016. The program of SPSS was used to analyze the results of the survey. The results of the current study shows that students spend a significant amount of their times on using Facebook.
\end{abstract}

\section{Keywords}

Facebook Impact, Social network, Facebook usage

\section{INTRODUCTION}

Facebook is a social networking website which launched in 2004 by Facebook Inc. it was initially developed by student at Harvard University which was Mark Zuckerberg. Facebook had 1 billion active users around the world in 2012. This number raised to 1.59 monthly active users (Statista, 2016).

Facebook is the leader of the social networking website which has more users compare to other social websites (AKBIYIK, 2013). Facebook has usability to use and user have lots of feature to use in order to share photos, videos. Users also can add new friends, comments and messaging each other's (Servia-Rodríguez et al, 2013).

Facebook has five important advantages which are:

1. Students can frequently use it when they are bored.

2. It is easy to communicate to others.

3. Students feel free and relaxed in the Facebook environment.

4. Facebook provide facilities to identify other users.

5. It is a public area which can be seen by universities and others.

Despite the benefits of using Facebook, it has side effect on student life in university and particularly studying (Bicen and Cavus, 2011).

\section{Problem}

Facebook affects student's life and study at Charmo University. Some Students suffering from using Facebook because of being addicted to it. Facebook also impacts on student's behavior and performance. How Facebook do not let students to focus on their studying. These are problems which has been selected in this paper. Therefore, the aim of this paper is to detect the impact of Facebook on students at Charmo University.

\section{Methodology}

\section{Participants}

100 Undergraduate students participated from different faculties at Charmo University in this study. The sample of the participants was $56 \%$ female and $44 \%$ male. The survey was conducted during the 2016 spring.

\section{Instruments}

Data was collected by using online survey which was created by researchers. The survey includes three sections. The first section includes some question about participants. In the second section was consists of items related to time usage and effecting on studying. The last section was about health risk of using Facebook. 


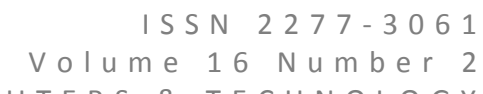

INTERNATIONAL JOURNAL OF COMPUTERS\& TECHNOLOGY

\section{Data Analysis}

Data was conducted by online survey and then the SPSS program is used to analyze the percentage, frequency and statistical analysis.

\section{Literature review}

\section{Facebook impact on physical health and social life}

Using Social Networking System (SNS) such as Facebook has side effect on student's health and social life. Using Facebook increase the chance of students to get Upper Respiratory Infection (URI) (Elgendi, 2015). According to the study has been conducted at undergraduate students which looks the history illness of 88 students from age 18-24. These students do not have any illness (Elgendi, 2015). Students had to complete a web based survey and follow up checking the symptom of URI. The survey include some questions related to the stress of being using Facebook. The result shows that $58 \%$ students are experiencing URI. The symptom of this disease are runny nose, headache, cough, sneezing and nasal congestion. This study illustrates that increasing rate of URI depends on increasing of using SNS. Facebook stress related to some factors for instance, anxiety because of delaying reply to a friend request, feeling guilty when rejecting friend request or unfriend a friend (Rouis et al, 2011). 31.7\% of the students said that leaving Facebook will decrease the stress and anxiety. Also, $43.9 \%$ of correspondent stated that using Facebook made social life harder which means it is hard to close to people (Elgendi, 2015).

Using Facebook a lot of time can impact on mental health. Some studies show that using Internet for lots of time make users addiction to it and listed in to game addiction and Internet sex addiction. Spectrum addiction disorder is a concept which is used by some researchers (Elgendi, 2015).

There are two different type of Facebook user such Facebook usage and Facebook addiction (Stieger, 2013). Facebook addiction results in depression, withdrawal, life problem and satisfaction. On the other hand, Facebook usage include looking at new feed, games and chatting. The study shows that Facebook works like a drug in virtual world of communication. One case study demonstrates that 24 year old girl in US had been using Facebook excessively. As a result, she lost her job and become mood and developed insomnia (Koc and Seval, 2013).

\section{Facebook impact on undergraduate students}

Facebook is a time stealer. Undergraduate students needs to manage their time in better way while Facebook usage wasting their time. Increasing usage of Facebook will have the side effect on students' performance in university (Kshirsagar and Kulkarn, 2015). According to Kaiser Family Foundation those students who spend less time on using Facebook are better in their grade compare to others. Despite the fact that students admits that Facebook is wasting their time. However, they cannot stop using it (farooqi et al, 2013).

Some students waste much more time on surfing on Facebook to look their friend's picture. According to the research $88 \%$ of students look at picture of friends and they feel about it so it changes the feeling of their friends while they want to study. Therefore, it declines the performance of students (Gafni and Deri, 2012). This study show that $65 \%$ of students use Facebook two hours per day. There were 103 undergraduate students participated from seven engineering department.

According to a study which 100 students were participated, students were asked how long they use Facebook per day (Bicen and Cavus, 2011). Figure (1) show that 2.24\% of participants use Facebook one hours a day, $28 \%$ of them use it for two hours, $16 \%$ use Facebook for more than three hours a day, 32\% use Facebook for more than four hours a day.

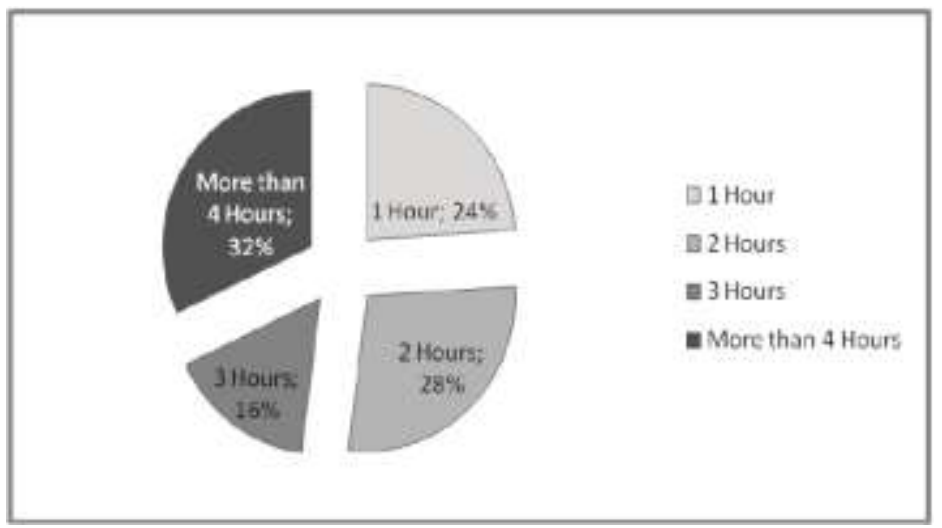

Figure 1 Distribution of Facebook usage habits of student's hour/day

\section{Result and discussion}

\section{Basic analysis of the survey}

The survey was answered by 100 students from different colleges at Charmo University. Participant gender were $56 \%$ female and $44 \%$ male. 
The graph shows the students' stage which they responded to the online survey. The percentage of students' first stage was $56 \%$, second stage $3 \%$, third stage $10 \%$ and fourth stage $31 \%$. Another question was how many years you used Facebook, the answer was $16 \%$ is used for 1 to 6 months, $8 \%$ is used for one year, $19 \%$ is used for two years and $57 \%$ is used for 4 years or more. Students were asked the habit of using Facebook usage to estimate the average number of hours to surf Facebook per day. $20 \%$ of students are using Facebook less than half an hour while 16\% of them using Facebook more than 4 hours (1=2 40, 3- 24). Next question was did Facebook has bad impact on your grade? The response was $29 \%$ of students' grade are affected by Facebook, 35\% of them are not affected and $36 \%$ of them are affected but not in a high degree.

The students were asked how many times that undergraduate students used Facebook at late night the response was $61 \%$ of them used it sometimes, $22 \%$ of them used for many times, $11 \%$ of them were not using it and $6 \%$ of them always using it. (Q8) $42 \%$ of them used Facebook sometimes during their study, 33\% of them were not used it, $22 \%$ of them responded that they used it and 3\% of them mostly used it. (Q9) related to the students study undergraduate students may need sometimes to back to their study after using Facebook. Therefore, $59 \%$ of them was not need any time to get back to study while $29 \%$ of them needed half an hour, $9 \%$ of them required 1 hour and $3 \%$ required more than 2 hours.

(Q10) students were asked if they want to reduce their Facebook usage. The result shows that $42 \%$ of the students tried to reduce their time to surf on Facebook so they succeed. However, 25\% of them tried to decrease Facebook usage. As a result, they could not decrease their Facebook usage. In addition, 33\% of them never tried to reduce their Facebook usage. (Q11) the study also found that $67 \%$ of undergraduate students will reduce their Facebook usage while $29 \%$ of them will use it same as before. (Q12)The most preferred Facebook tools usage habits of students. \%23.2 of the correspondent use Facebook for sociality. Some of them want to communicate with their friend by $60 \%$. Approximately $8 \%$ is using it for making new friends and $46 \%$ use it for educational purpose. Some of them use it for spending time and for fun by $25.3 \%, 29.5 \%$ respectively.

(Q13) students were asked about impact of Facebook usage on their eyes. $67 \%$ of them have side effect on their eyes, $28 \%$ of them do not know if they have eye problems and $5 \%$ of them do not have it.

(Q14)The study found that $46.5 \%$ of them has headache while $53.5 \%$ do not have it. (Q15) 26.3 of the students were determined as an addiction user on Facebook while $73.7 \%$ of them are not addicted.

\section{Advanced analysis of the survey by SPSS}

A one-way ANOVA was conducted to compare the effect of FB usage on undergraduate students' academic performance at Charmo University. The reason of using ANOVA is, The ANOVA is an essential test because it allows researchers to see for example how effective two different kinds of treatment are and how durable they are (Chandrakantha, 2014).

The result of the Effect of Facebook on academic performance for undergraduate students based on the survey, are divided into three parts depended on types of factors.

\section{Effect of gender}

Gender is one of the factors that has been considered in the survey. Gender as a factor is tested versus all dependent variables. Table 1 shows that the effect of gender on eyelmpact is significant because the $p$ value is less than $.05, f(1,98)$ $=8.347, p=.005$. Therefore, female has more eye problems than male due to FB usage.

Table 1 ANOVA between gender and eyelmpact

\section{ANOVA}

eyelmpact

\begin{tabular}{|l|r|r|r|r|r|}
\hline & Sum of Squares & df & Mean Square & F & Sig. \\
\hline Between Groups & 6.263 & 1 & 6.263 & 8.347 & .005 \\
Within Groups & 73.527 & 98 & .750 & & \\
Total & 79.790 & 99 & & & \\
\hline
\end{tabular}

\section{Effect of age}

Participants who have used FB for years (yearUsage), age parameter has impact on it. Therefore, the analysis of ANOVA revealed a significant difference, $f(2,97)=7.077, \quad p=.001$. Figure (1) illustrate the significant value of age upon yearUsage. 


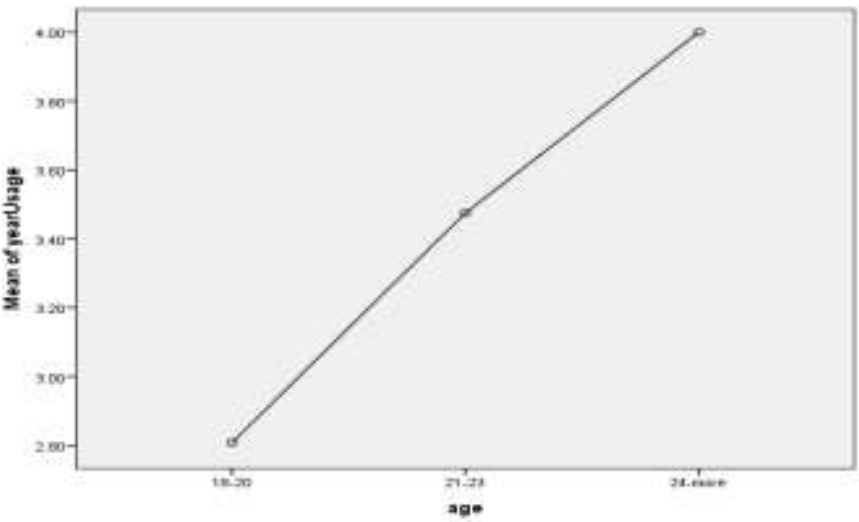

Figure 2 Means plot age vs yearUsage

Participants who have used FB during their study (studyUsage) have a significant differences depends on the age parameter, $f(2,97)=5.602, \quad p=.005$

\section{Effect of stage}

The stage factor has a great impact on the study due the significant result.

In the table 1,2 show the effect of stage on yearUsage and studyUsage with the p-value $(.031, .008)$ respectively.

Table 2 ANOVA between stage and yearUsage

\section{ANOVA}

yearUsage

\begin{tabular}{|l|r|r|r|r|r|}
\hline & Sum of Squares & df & Mean Square & F & Sig. \\
\hline Between Groups & 11.076 & 3 & 3.692 & 3.081 & .031 \\
Within Groups & 115.034 & 96 & 1.198 & & \\
Total & 126.110 & 99 & & & \\
\hline
\end{tabular}

Table 3 ANOVA between stage and studyUsage

\section{ANOVA}

studyUsage

\begin{tabular}{|l|r|r|r|r|r|}
\hline & Sum of Squares & df & Mean Square & F & Sig. \\
\hline Between Groups & 7.868 & 3 & 2.623 & 4.135 & .008 \\
Within Groups & 60.882 & 96 & .634 & & \\
Total & 68.750 & 99 & & & \\
\hline
\end{tabular}

Moreover, the stage also has the impact on the headache based on the survey.

Table 4 ANOVA between stage and headache

\section{ANOVA}

headache

\begin{tabular}{|l|r|r|r|r|r|}
\hline & Sum of Squares & df & Mean Square & F & Sig. \\
\hline Between Groups & 2.612 & 3 & .871 & 3.748 & .014 \\
Within Groups & 22.298 & 96 & .232 & & \\
Total & 24.910 & 99 & & & \\
\hline
\end{tabular}




\section{Conclusion}

There are three factors has been considered in the survey such as stage, age and gender while there are a lot of dependent variables. Some essential points are obtained from the advanced analysis of the survey which are presented below:

1. Stage has the greatest impact as independent variable. The second and third are age and gender respectively.

2. The effect of stage is gradually increased on yearUsage, studyUsage and headache from first stage to fourth stage (shows in figure $3,4,5$ in appendix)

3. The effect of age is dramatically raised on yearUsage and studyUsage from age if 18-20 to 24-more.

4. The third impact is gender which has an impact on eyelmpact variable. Therefore, female has more eye problems than male due to FB usage.

\section{Acknowledgement}

We would like to thank Charmo University for sponsoring our research paper.

\section{References}

1. AKBIYIK, C. (2013) 'Effects of Social Networks on Social Life of Undergraduate Students', Middle Eastern \& African Journal of Educational Research, 4(6), pp. 4-10.

2. Bicen, H. and Cavus, N. (2011) 'Social network sites usage habits of undergraduate students: case study of Facebook', Procedia - Social and Behavioral Sciences, 28, pp. 943-947.

3. Chandrakantha, L. (2014), "Learning ANOVA concepts using simulation," American Society for Engineering Education, 2014 Zone 1 Conference, pp. 1-5.

4. Elgendi, H. (2015) 'The Effect of Facebook on College Student's', International Journal of Networks and Communications, 5(2), pp. 37-40.

5. Farooqi, H., patel, H. and Muhammad, H. (2013) 'Effect of Facebook on the life of Medical University students', International Archives of Medicine, 6.

6. Gafni, R. and Deri, M. (2012) 'Costs and Benefits of Facebook for Undergraduate Students', Interdisciplinary Journal of Information, Knowledge, and Management Special Section on Social Networking, Teaching, and Learning, 7, pp. 45-61.

7. Koc, M., and Seval, G. (2013) "Facebook Addiction Among Turkish College Students: the Role of Psychological Health, Demographic, and Usage Characteristics." Cyberpsychology, Behavior, and Social Networking. 16(4). pp. 279-284.

8. Kshirsagar, V.S. and Kulkarn, S.A. (2015) 'A Study on Effects of Social Networking Sites as an Educational Tool on College Students', International Journal of Science and Research (IJSR), 4(1), pp. 1814-1816.

9. Leelathakul, N. and Chaipah, K. (2013) 'Quantitative effects of using facebook as a learning tool on students' performance', Computer Science and Software Engineering (JCSSE), 10th International Joint Conference, pp. 87-92.

10. Rouis, S., Limayem, M. and Salahi, E. (2011) 'Impact of Facebook Usage on Students' Academic Achievement: Role of Self-Regulation and Trust', Electronic Journal of Research in Educational Psychology, 9(3), pp. 961-994.

11. Servia-Rodríguez, S., J. Pazos-Arias, J., P. Díaz-Redondo, R., and Fernández-Vilas, A. (2013) 'Inferring Contexts From Facebook Interactions: A Social Publicity Scenario', IEEE Transactions on Multimedia, 15(6), pp. 1296-1303.

12. Statista (2016) Number of monthly active Facebook users worldwide as of 1 st quarter 2016 (in millions). Available at: http://www.statista.com/statistics/264810/number-of-monthly-activefacebook-users-worldwide/ (Accessed: 25 March 2016).

13. Stieger, S, C Burger, M Bohn, and M Voracek. (2013) "Who Commits Virtual Identity Suicide? Differences in Privacy Concerns, Internet Addiction, and Personality between Facebook Users and Quitters." Cyberpsychology, Behavior, and Social Networking. 16(9), pp. 629-634. 


\section{Appendix}

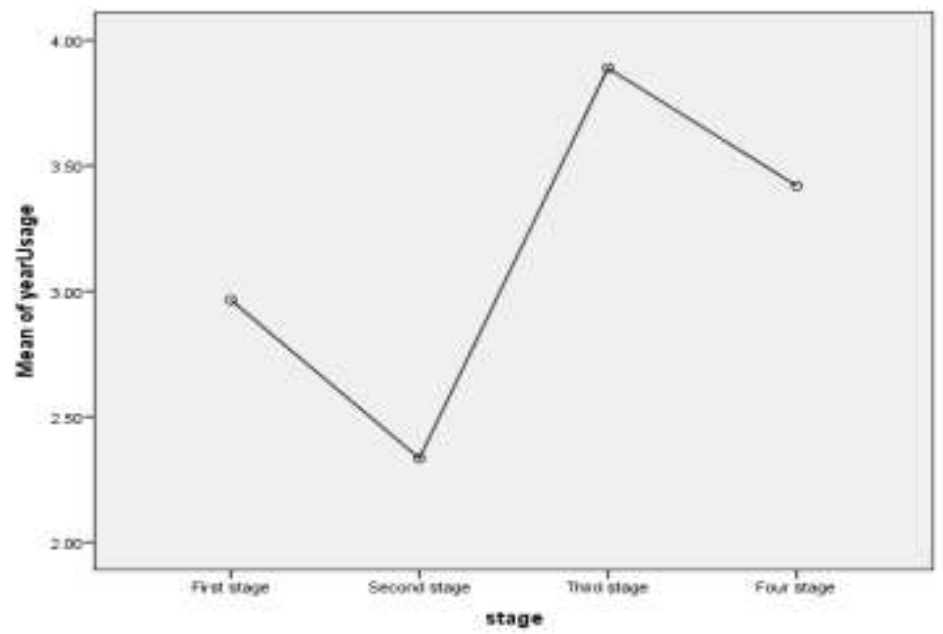

Figure 3 Means plot stage vs yearUsage

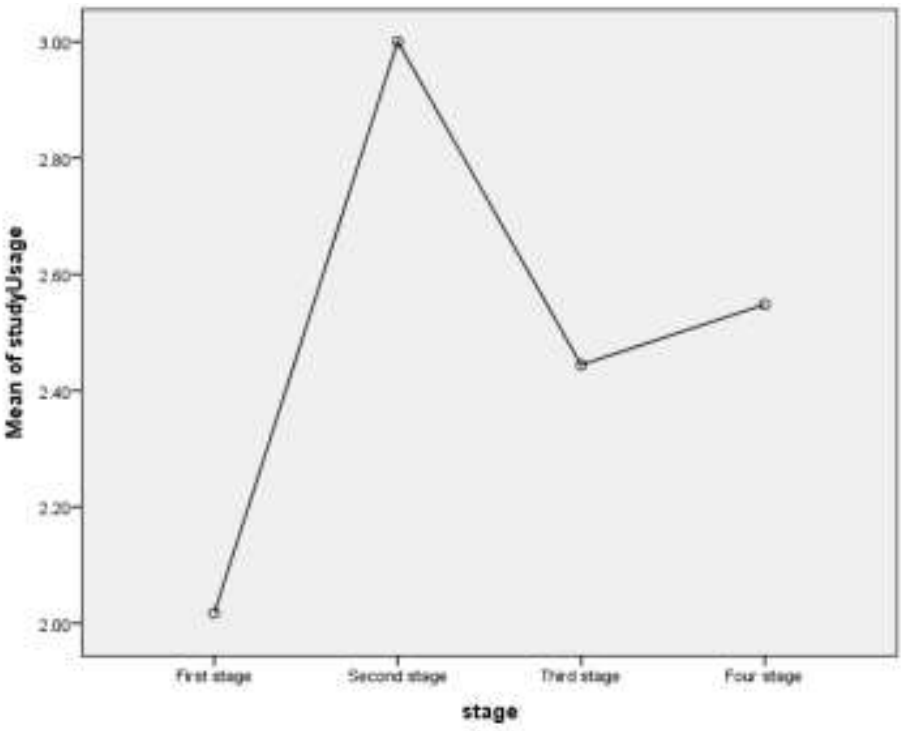

Figure 4 Means plot stage vs studyUsage

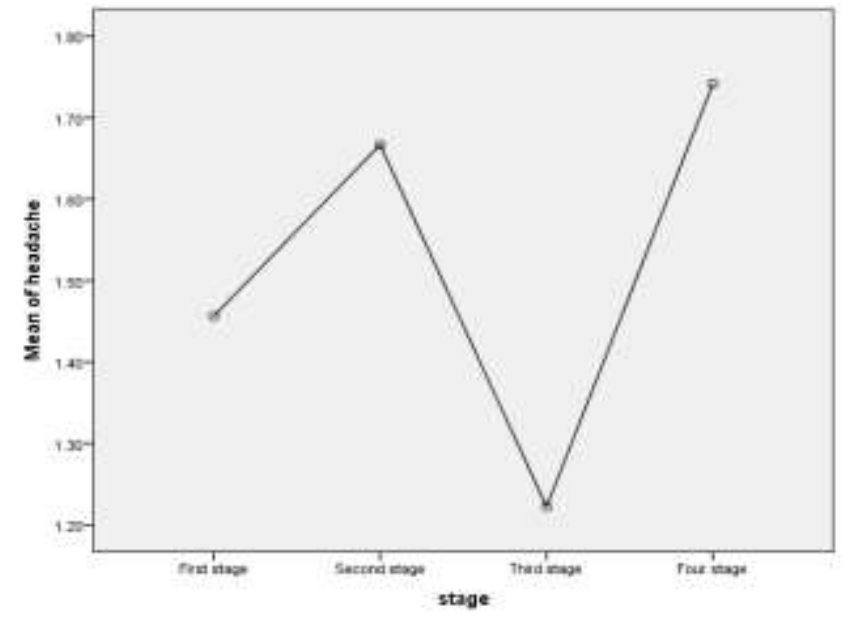

Figure 5 Means plot stage vs headache 